\title{
OIL POLLUTION IN THE SOUTHEASTERN BALTIC SEA IN 2009-2011
}

\author{
O.Yu. Lavrova", M.I. Mityagina ${ }^{2}$, A.G. Kostianoy, ${ }^{3,4}$, A.V. Semenov ${ }^{4}$ \\ ${ }^{1,2}$ Space Research Institute, Russian Academy of Sciences, \\ Moscow, Russia, Profsoyuznaya Str. 84/32, \\ ${ }^{1}$ E-mail: olavrova@iki.rssi.ru \\ ${ }^{2}$ E-mail: mityag@iki.rssi.ru \\ ${ }^{3}$ P.P. Shirshov Institute of Oceanology, Russian Academy of Sciences, \\ Moscow, Russia, Nakhimovsky Pr.36, \\ E-mail: kostianoy@gmail.com \\ ${ }^{4}$ S.Yu. Witte Moscow University, \\ Moscow, Russia, Second Kozhukhovsky Pr.12, Build.1, \\ E-mail: semen7777@gmail.com
}

\begin{abstract}
From January 2009 to April 2012 a satellite survey of the central and southeastern parts of the Baltic Sea was carried out by the Space Radar Laboratory at the Space Research Institute of Russian Academy of Sciences (RAS). The main attention was focused on the detection of oil pollution as well as biogenic and anthropogenic surfactant films. The basic data are high resolution radar images obtained by advanced synthetic aperture radar (ASAR) on board of the Envisat satellite of the European Space Agency. Remotely sensed data in visual and infrared (IR) bands acquired by sensors MERIS Envisat, MODIS-Terra and -Aqua, and AVHRR NOAA nearly simultaneously with the ASAR images, were processed and analysed in order to facilitate the discrimination between different types of surface pollutants, to understand a comprehensive features of meteorological and hydrodynamic processes in the sea area of investigation, and to reveal factors determining pollutants spread and drift. The regions of the most intense oil pollution are outlined.
\end{abstract}

Keywords: Southeastern Baltic Sea, oil pollution, satellite monitoring, synthetic aperture radar, Envisat, MODIS-Terra and Aqua

\section{Introduction}

In recent years a number of new oil terminals have been built in the Baltic Sea area, resulting in increased transport of oil by ships and, consequently, an increased risk of accidents (Kostianoy and Lavrova, 2014a). Transportation is a reason of $45 \%$ of the oil in the sea while an offshore production is a source of only $2 \%$ of the oil pollution in the World Ocean. In the Baltic Sea about 2,000 large ships and tankers are at sea every day (Global Marine..., 2012). Thus, shipping activities, including oil transport and oil handled in harbours, have major negative impact on the marine environment and coastal zone in the Baltic Sea (Kostianoy and Lavrova, 2014a).

Public interest in the problem of oil pollution arises mainly during dramatic tanker catastrophes (Kostianoy and Lavrova, 2014b). The catastrophic oil spills are quite rare and caused, generally, by tanker crashes, as a rule, such events are broadly covered by mass media. Much less attention is paid to oil contamination of the sea surface caused by routine activities on ships. Ship-related operational discharges of oil include: (i) discharge of bilge water from machinery spaces; (ii) operational discharges of oil from machinery spaces to the sea; (iii) discharge of tank-washing residues and oily ballast water.

Oil and oily residue discharges from ships represent a significant threat to marine ecosystems. These discharges may occur during normal activities or may be accidental or illegal. Oil spills cause the contamination of seawater, shores, and beaches, which may persist for several months and even years (Kostianoy and Lavrova, 2014c).

As concerns oil exploitation at sea and on the coast, offshore operations have been taking place for some years in Polish waters (two jack-up rigs); until recently Germany operated two platforms very close to the coast; in March 2004 Russia started the oil production at continental shelf in the waters between the Kaliningrad area (Russian Federation) and Lithuania, as well as there are Latvian plans to drill for oil in the waters between Latvia and Lithuania (Global Marine..., 2012). So far as the Baltic Sea ecosystem undergoes growing human-induced impacts, especially associated with an increasing oil transport and production, one of the main tasks in the ecological monitoring of the Baltic Sea is an operational satellite 
and aerial detection of oil spillages, determination of their characteristics, establishment of the pollution sources and forecast of probable trajectories of the oil spill transport.

The authors of the present paper have the ten years experience in satellite monitoring of the Baltic Sea which includes three stages:

I. In June 2003 LUKOIL-Kaliningradmorneft (Kaliningrad, Russia) initiated a pilot project, aimed to the combined monitoring of the southeastern Baltic Sea, in connection with a beginning of oil production at continental shelf of Russia in March 2004. Operational monitoring was performed in June 2004 - November 2005 on the base of daily satellite remote sensing (AVHRR NOAA, MODIS, TOPEX/Poseidon, Jason-1, ENVISAT ASAR and RADARSAT SAR imagery) of sea surface temperature (SST), sea level, chlorophyll concentration, mesoscale dynamics, wind and waves, and oil spills (Kostianoy et al., 2005, 2006, 2014).

II. Starting from 2009 up to the April 2012 a satellite survey of the central and southeastern Baltic was carried out by the Space Radar Laboratory at Space Research Institute of Russian Academy of Sciences (RAS). The main attention was focused on the detection of oil pollution as well as biogenic and anthropogenic surfactant films (Mityagina et al., 2012; Kostianoy et al., 2014a).

III. In 2010-2013 daily satellite monitoring of construction and exploitation of marine gas pipeline "Nord Stream" in the Gulf of Finland was carried out by the Ocean Experimental Physics Laboratory at P.P. Shirshov Institute of Oceanology of RAS. It was focused on the suspended matter and oil pollution in the area of the pipeline construction, as well as on the detection of different effects, related to the exploitation of the pipeline, in the sea surface temperature (SST), suspended matter, chlorophyll concentration, sea surface roughness, and sea ice fields (Grishin and Kostianoy, 2012a,b; 2013; Kostianoy et al., 2014b).

In this paper we will refer on the results obtained during stage II, which basically remained unpublished in English editions.

\section{Tasks and technical means}

The main attention was focused on the detection of anthropogenic and biogenic surface films. Four main types of sea surface polluting films were investigated, caused by: (i) oily wastewaters discharged by watercrafts; (ii) sewage discharge, river and coastal outflows, containing anthropogenic and natural pollutants; (iii) increased biological productivity, including chlorophyll life cycle and intensive algal bloom.

The surface pollution and sea dynamics monitoring was based on receiving; processing and combined analysis of satellite imagery obtained by various sensors installed on different satellites and operating in different bands of electromagnetic waves. The basic data were high resolution radar images obtained by synthetic aperture radars (SAR) ASAR Envisat and SAR ERS-2. The SARs are the most important devices for satellite monitoring of the sea surface condition and for pollution level assessment due to the following reasons: (i) twenty-four-hour operation capacity, image parameters being independent on solar illumination; (ii) radar measurement can be performed under any weather conditions, as the atmosphere is nearly transparent for SAR microwave radiation; (iii) dielectric property of water at microwave frequencies is homogeneous, and the fluctuation of scattered signal is induced solely by parameters of sea surface roughness which facilitates satellite imagery interpretation; (iv) high spatial resolution of advanced space SAR permits detecting even insignificant oil pollution with required accuracy.

Nevertheless, detection of the sea surface oil pollution based only on SAR data is rather problematic because of the difficulty in distinguishing oil slicks, especially at lower wind speeds, from other phenomena known as oil "look-alikes" (Espedal and Johannessen, 2000; Brekke and Solberg, 2005). The wave damping may be related not only to oil films, but also to biogenic films, land-shadowed areas near coasts, rain cells, zones of upwelling, young ice, and oceanic or atmospheric fronts (Espedal and Wahl, 1999). The contrast between a spill and surrounding water, and therefore the probability of detecting pollution films, depends both on the amount and type of oil as well as on environmental factors such as wind speed, wave height, SST, currents and current shift zones.

The discrimination of anthropogenic and natural (biogenic and mineral) films is one of the most difficult tasks. Our experience gained from a number of monitoring campaigns shows that this problem can be successfully solved on the base of combined use of satellite data taken in visual, IR, microwave ranges, and oceanographic and meteo information (Lavrova et al., 2011). This data is obtained by different sensors mounted on board of different Earth observation satellites. The key problem consists in combining data varying in physical, spatial, temporal resolution and image dimension. 
The technology of multisensor satellite monitoring of the sea surface was developed and tuned by a consortium of research teams, including the research groups from Space Research Institute, P.P. Shirshov Institute of Oceanology, Geophysical Center of the Russian Academy of Sciences, and Marine Hydrophysical Institute (Kostianoy et al., 2005; 2006; 2007; 2014a; Shcherbak et al., 2008; Lavrova et al., 2009; 2011).

Data in visual and IR bands taken by MERIS Envisat, MODIS Terra/Aqua and AVHRR NOAA nearly simultaneously with the ASAR images, were involved into consideration in order to facilitate the discrimination between different types of surface pollutants, to reveal the of meteorological and hydrodynamic processes in test areas, and to determine factors governing pollutants spread and drift. Supplementary data were obtained also from scanning radiometers ETM+ Landsat-7 and TM Landsat-5. Meteorological data, required for the analysis of satellite data, were provided by coastal meteo stations.

\section{Basics of radar detection of the sea surface oil pollution}

Satellite monitoring of oil pollution of the sea surface is based on the capacity of satellite-borne radars to reveal sea surface areas (so-called film slicks) covered by surface films. Surface films lead to reduced interaction of ocean waves and wind as well as to attenuation of the resonance gravity-capillary component of surface waves. In this case some smooth areas (slicks) appear on the sea surface and form areas of reduced backscattered signal in radar image which can be considered as indicators of the sea surface pollution (Alpers and Huhnerfuss, 1989; Jenkins and Jacobs, 1997; Mityagina and Churumov, 2006).

In the course of radar experiments there was investigated the correlation between radar backscattering contrasts, caused by an oil film covering the surface, and such parameters as sea surface waves, wind speed and direction, the condition of near-surface layer of atmosphere. As a result the optimal conditions for satellite pollution monitoring were specified, namely wind speed - 3-9 m/s, and wave heights - up to $1.25 \mathrm{~m}$, stable stratification of the atmosphere - ocean boundary layer. Furthermore, the near-surface wind is the most important factor effecting the reliable detection of oil pollution on the sea surface via radar imagery (Gade, 2006). Under the wind speed exceeding 9-10 m/s both oil and biogenic polluting films cannot be discerned in radar images.

Under windless conditions or under weak unsteady winds the capillary-gravity component of the sea surface wave field may not develop. This results in attenuation of backscattered signal. Moreover, in radar images obtained under weak near-surface wind there are usually a large number of low backscatter areas that are not related to the presence of surface films. The existence of these low scattering (dark) areas in radar images increases the "false alarm" probability in oil pollution monitoring.

The contrasts between the spill area and the sea surface around it are determined by a number of parameters: wind speed, wave height, quantity and a type of spilled oil, etc. The shape of spill may vary depending on whether it was discharged by a moving or a stationary object.

It should be noted that the detection of oil spills in Baltic Sea area by means of satellite radar imagery is rather complicated due to unstable meteorological conditions. Complicate hydrometeorological conditions - too high or too low surface wind (calm sea, wind shadow), algal bloom, ice cover, intensive precipitation, passing by of atmospheric and wind fronts, atmospheric convection and atmospheric gravity waves - all this make difficult the detection and identification of spills.

The main factors making the detection of the surface manifestations of the internal waves in radar images difficult are the active atmospheric processes in this area resulting in considerable variation of the near-surface wind field. Of course atmosphere is transparent for radar signal and atmospheric processes are displayed in radar images only via inhomogenities of the gravity-capillary component of the seasurface wave field. Resulted from mesoscale processes wind field variations modulate short gravity waves at the sea surface resulting in the inhomogenities of the backscattered radar signal distribution.

We found that imprints of atmospheric phenomena cover the major part of practically every radar image taken in this region, and the variations of radar signal intensity they introduce are rather high. Often it makes practically impossible to identify manifestations oily spillages at the sea surface.

\section{Main results of satellite monitoring of the sea surface oil pollution}

Fig. 1 shows the cumulative map of oil spills revealed from satellite radar data in the southeastern part of the Baltic Sea during the time period from January 2009 till December 2011. It is possible to find out regions of most frequent discharges. They are:

(1) The main shipping route eastward of Gotland Island;

(2) Shipping routes to the Klaipeda and Liepaja ports; 
(3) Area northward of the Hel Spit (Gdansk Bay);

(4) The part of Gdansk Bay in the vicinity to the entrance to Kaliningrad Canal.

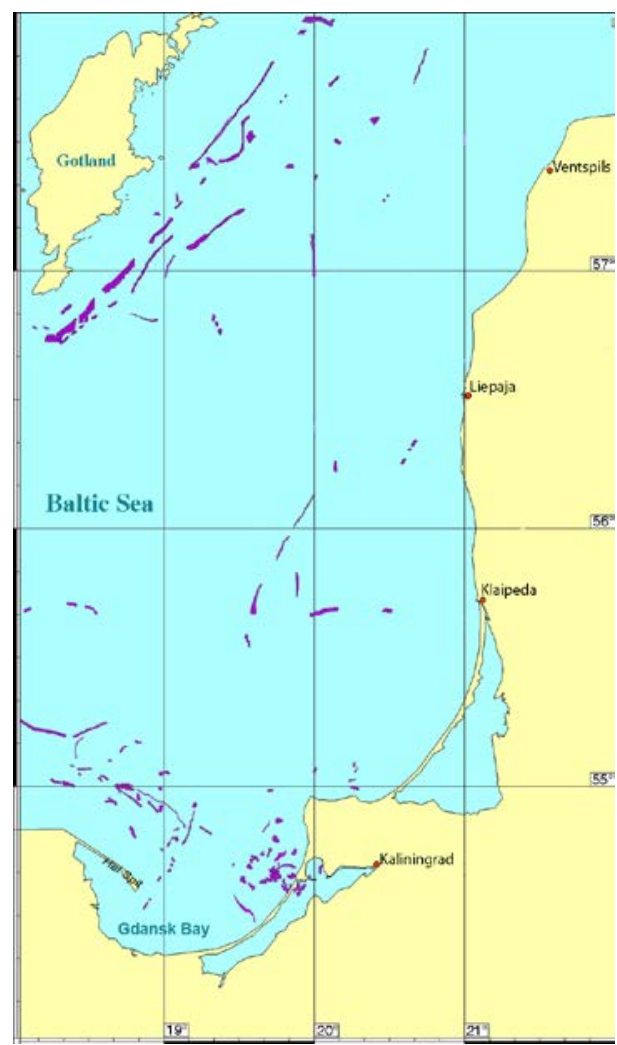

Figure 1. Map of oil spills revealed from satellite radar data in the southeastern part of the Baltic Sea in 2009-2011

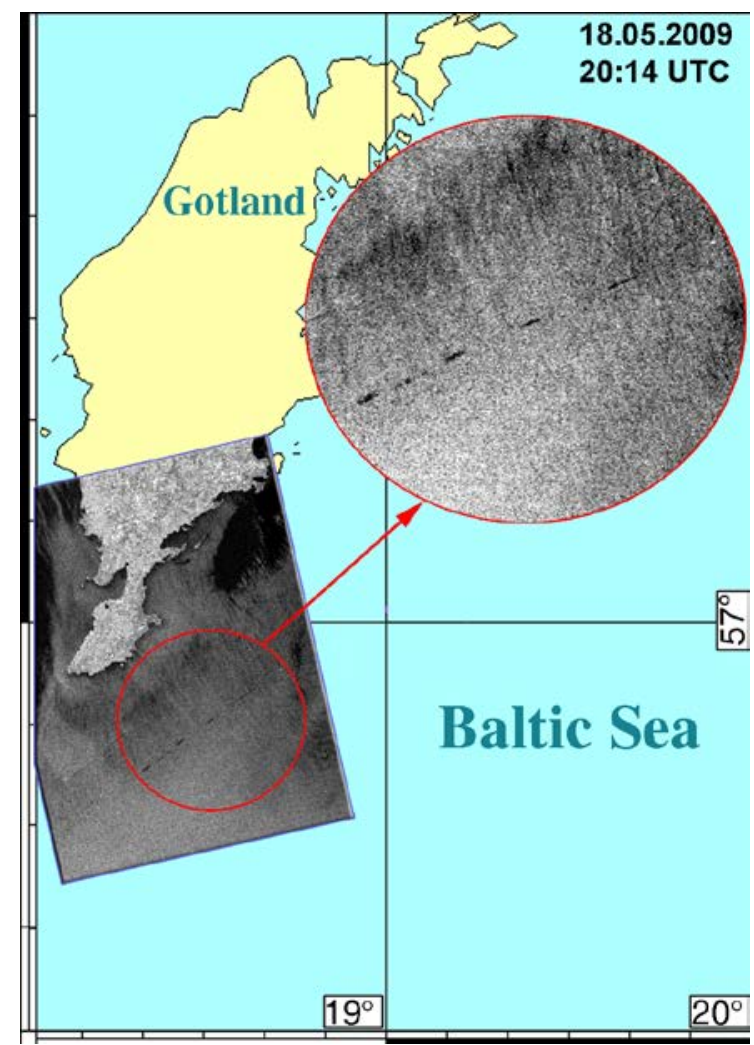

Figure 2. ASAR Envisat, 18.05.2009, 20:14 UTC. Oil spills chain. Total length - $30 \mathrm{~km}$. Total surface $-5.1 \mathrm{~km}^{2}$

The features of sea surface oil pollution revealed in radar imagery and typical for these regions will be discussed herein. We detected plenty pollution events along the main shipping route eastward of Gotland Island. All these events are caused by spillages of oil-containing waters from moving ships. These spillages appear as straight dark (reduced signal) stripe in radar image following the ship route leading from south-west to north-east. Some ships continue dumping wastewaters for dozens of kilometers on their way. Quite often ships discharge wastewaters several times while they are moving. Such examples are shown in Figs. 2 and 3. Fig. 2 shows a well-defined dashed spill of nearly $30 \mathrm{~km}$ long which ends by a bright point indicating the position of a moving ship. The spillage was conducted shortly before the radar image acquisition and the film has just started to spread, the closer to the ship the narrower the spill and one can observe high radar contrast between the spill area and the sea surface.

The example shown in Fig. 3 is characterized by wider film spreading under the influence of wind and waves and lower contrasts of the dashed spillage stretching for more than $50 \mathrm{~km}$. The latter discharge took place a few hours before satellite pass over the area of interest and the responsible ship-culprit could not be found. Apparently spillage was produced in several stages. The total polluted surface area had reached $105 \mathrm{~km}^{2}$ by the moment of radar image acquisition. This is the biggest spillage detected over the period of monitoring.

Wind has a great direct and indirect effect on the structure of a spill. Under the direct influence of the wind the film shifts over the sea surface, oil being accumulated on the leeward of the patch. Moreover, near-surface wind induces dynamic processes in the upper layer of the sea. The Lengmuir circulation is the most common process which is caused by wind driven spiral circulations of alternating directions with the axis almost parallel to the wind. Inside a vortex water moves in the plane perpendicular to the wind velocity vector. Thus on the sea surface there appear alternating divergence and convergence zones, oil being concentrated in the latter. An oil spill transforms into streaks that are referred to as "comb-like structure”. Such transformation of the spills left by a moving ship can be seen in Fig. 3. 
Spillages detected in the radar images taken over the central part of the area of interest along the shipping routes leading to Klaipeda and Liepaja are characterized by lesser lengths and are less numerous.

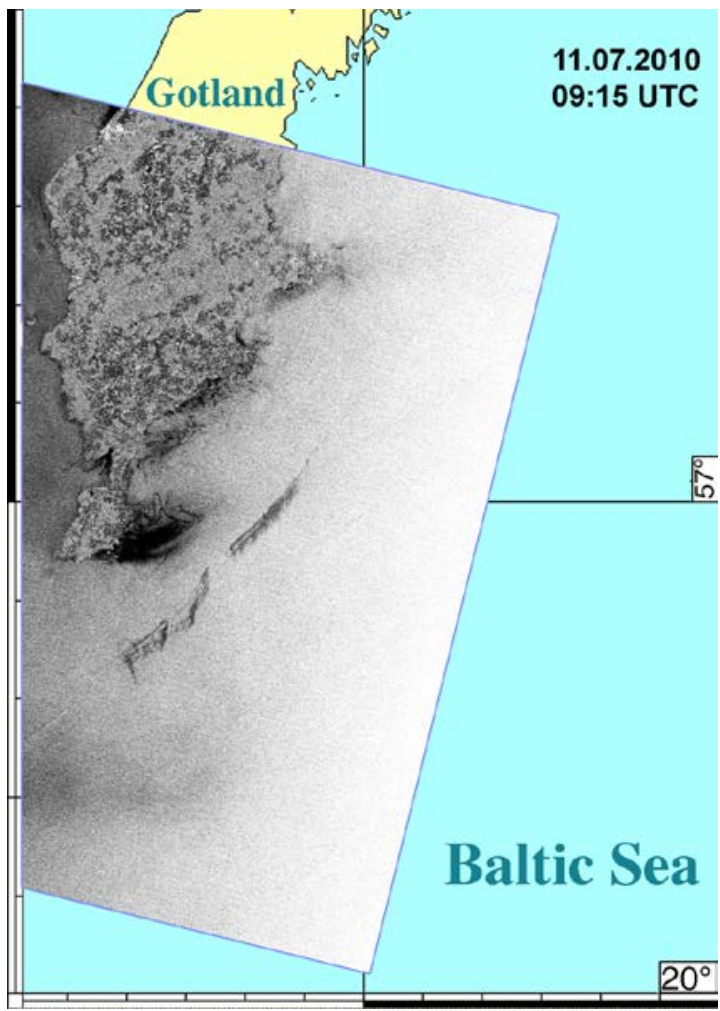

Figure 3. ASAR Envisat, 11.07.2010, 09:15 UTC. Weathered oil spills chain. Total length - $51 \mathrm{~km}$, total surface - $105 \mathrm{~km}^{2}$

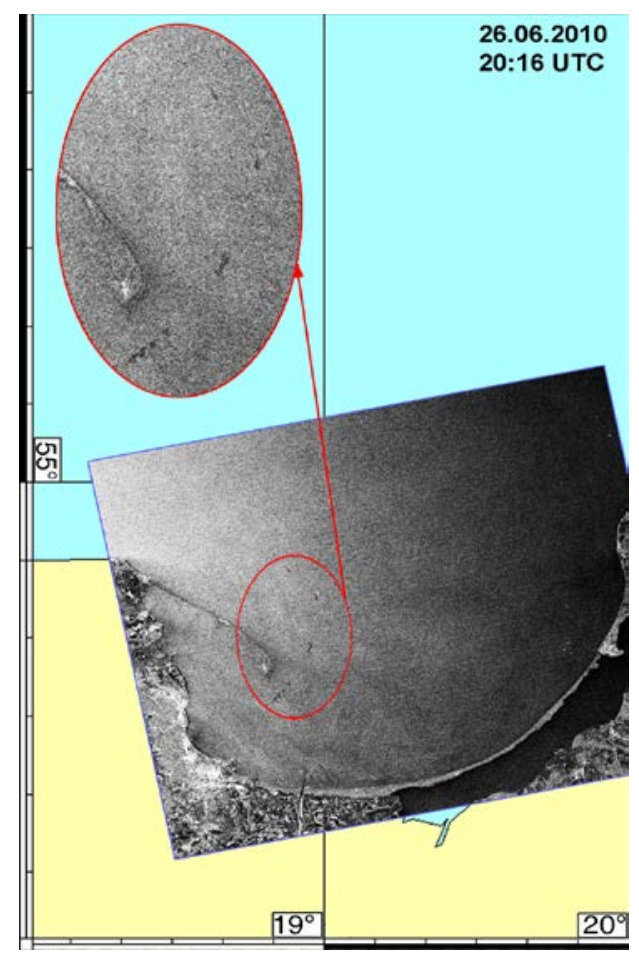

Figure 5. ASAR Envisat, 26.06.2010, 20:16 UTC. Multiple spillages from a moving ship Total length - $30 \mathrm{~km}$, total surface $-6.8 \mathrm{~km}^{2}$

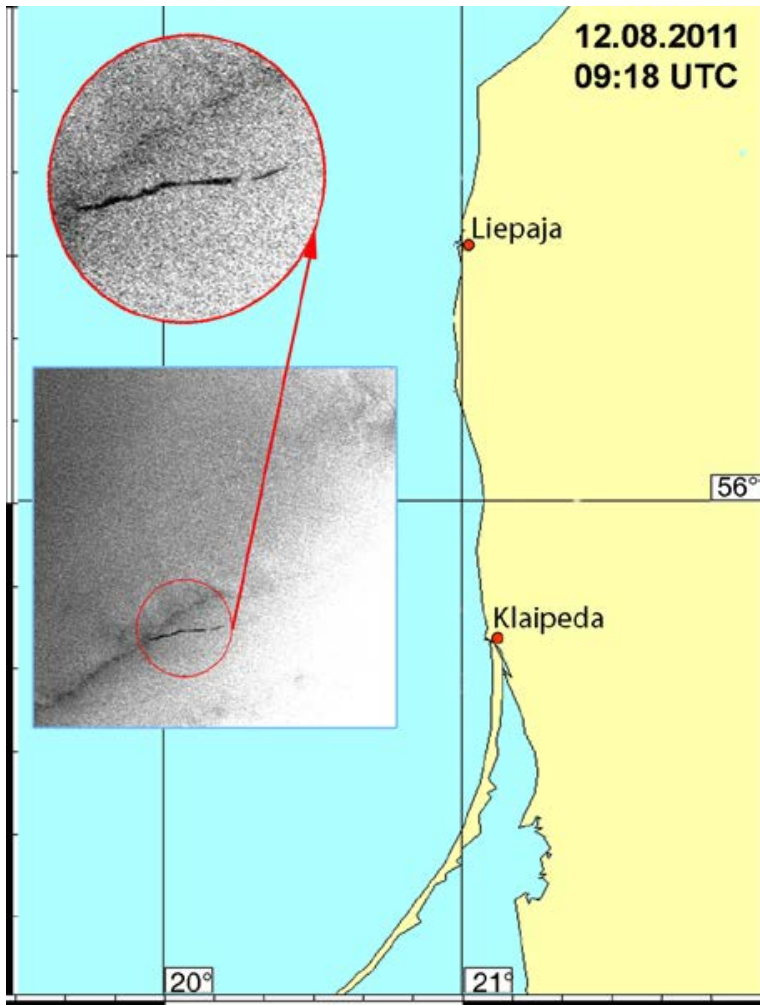

Figure 4. ASAR Envisat, 12.08.2011, 09:18 UTC. Oil spill from the moving vessel. Length $-12.5 \mathrm{~km}$, surface $-6 \mathrm{~km}^{2}$

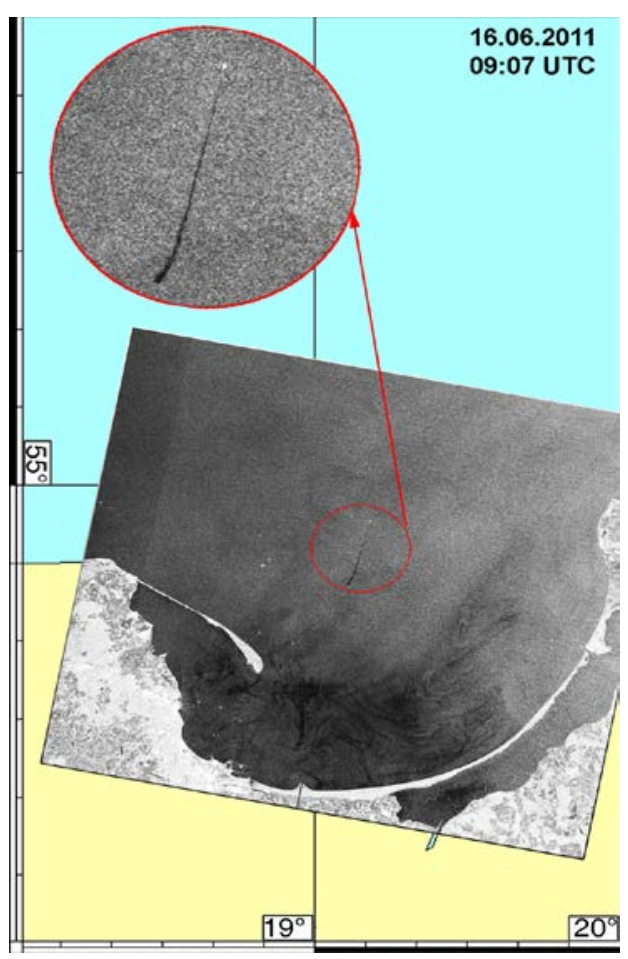

Figure 6. ASAR Envisat, 16.06.2011, 09:07 UTC. Fresh oil spill from a moving vessel. Length -15.7 km 
This may be due to the less intensive shipping traffic in this area. Many of detected pollution events were weathered oil spills characterized by wider film spreading and lower radar backscattering contrasts. A weathered spill of $12.5 \mathrm{~km}$ long left by a ship moving to/from the port of Klaipeda can be easily seen In Fig. 4. The spill shape is distorted due to local currents and near-surface winds and the narrowing of its most fresh part is not obvious. It is impossible also to identify explicitly a ship responsible for the spill.

Numerous spillages were detected in the Hel Spit area. Many of them have the form of enveloping curve duplicating the main shipping route leading from the port of Gdansk to southwestern ports of Baltic Sea and Dutch Straits and going round the Hel Spit. An example of this kind of spillages is shown in Fig. 5. It depicts a multiple spillage spread under the influence of winds and waves.

Other spillages in this area are stretched in north-eastern direction along the route leading to the ports of eastern Baltic. In Fig. 6 is given an "ideal” example of how fresh track of discharged wastes is depicted in a satellite image. The ASAR Envisat image a section of which is shown in the Fig.6 was taken in the area of Gdansk Bay under light wind and light sea surface disturbance.

The dark stripe depicting the spillage becomes narrower to north-east, which indicates that the ship - culprit discharged wastewaters moves in this direction. Bright image point in the north-eastern end of the stripe demonstrates the present locations of the ship. The wastewater stripe extends for $15.7 \mathrm{~km}$.

Pollution events detected in Gdansk Bay near the Pilava Strait (Kaliningrad Canal) are quite different from the ones described before. The water contamination in this area is mainly caused by wastewaters containing oil dumped from motionless ships in the anchorage site. Large number of spills having relatively small areas is detected in this area regularly. An example of typical situation in this area is shown in Fig. 7. But sometimes oily films spread over a large area under the influence of near- surface winds and surface waves. This situation is shown in Fig. 8, the total polluted surface area is of about $30 \mathrm{~km}^{2}$.

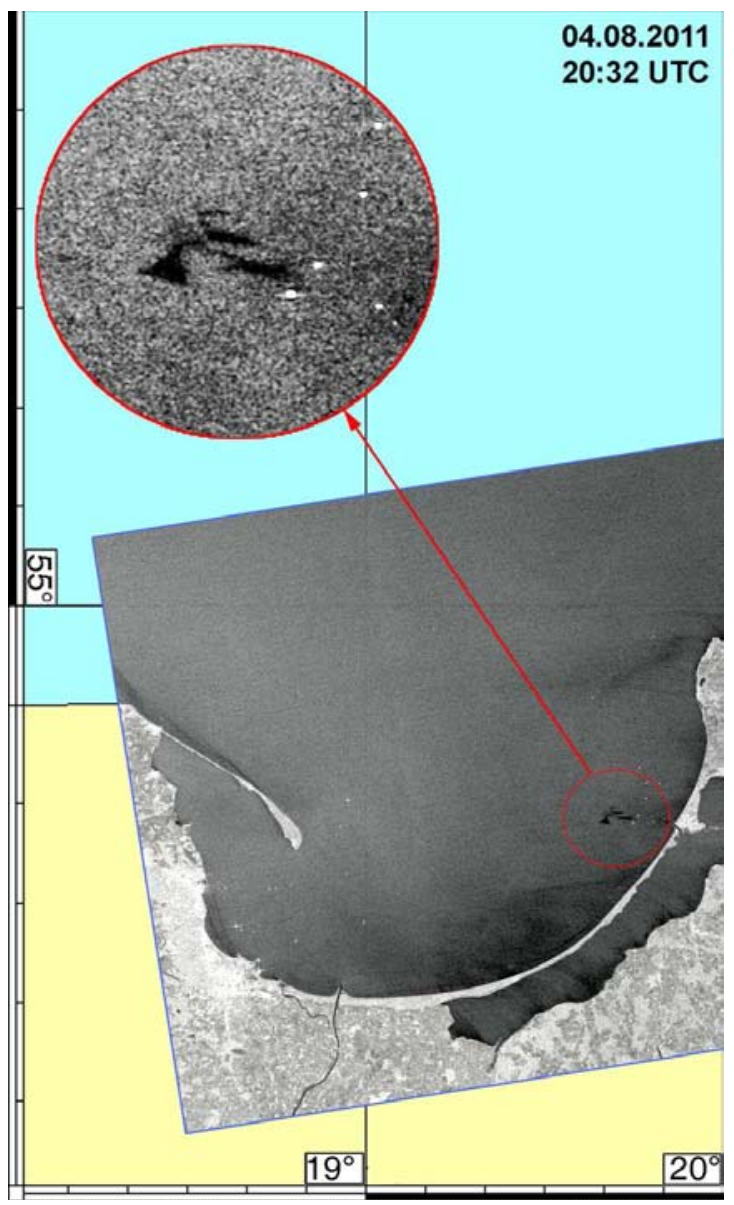

Figure 7. ASAR Envisat, 04.08.2011, 20:32 UTC. Total surface $-4.64 \mathrm{~km}^{2}$

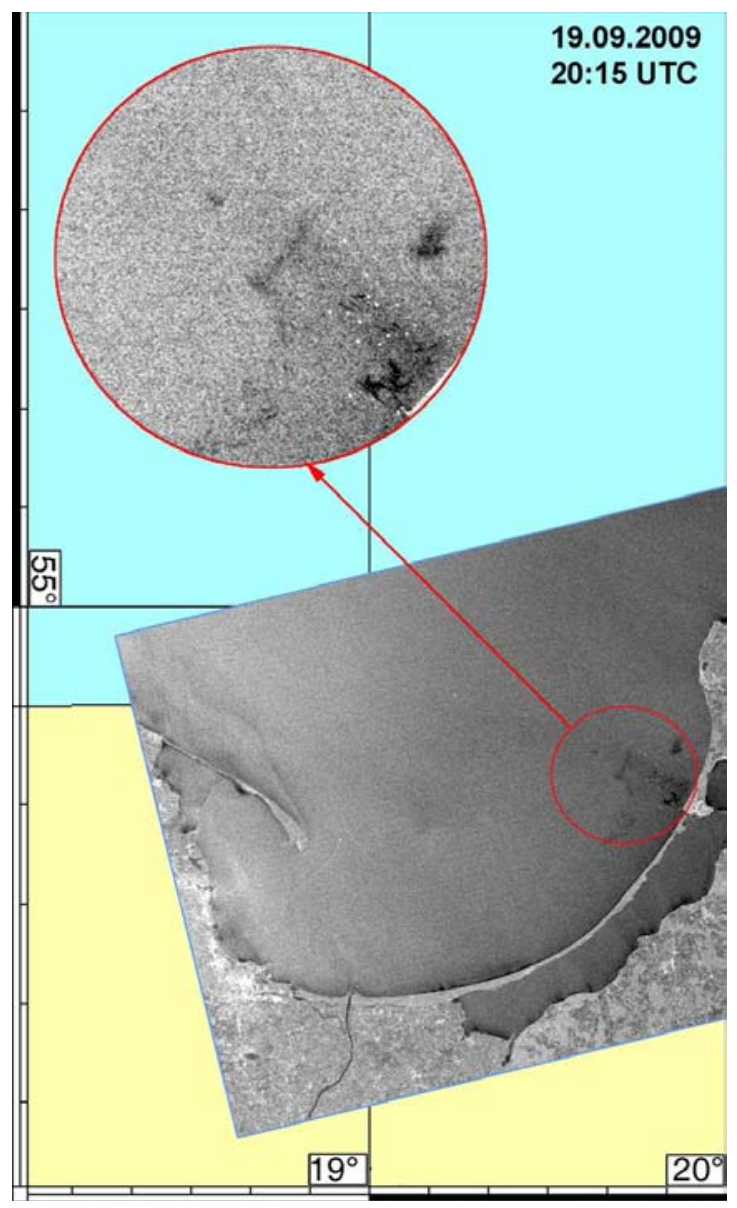

Figure 8. ASAR Envisat, 19.09.2009, 20:15 UTC. Total surface $-31.4 \mathrm{~km}^{2}$ 


\section{Summary of oil spills in the southeastern Baltic Sea revealed from satellite SAR/ASAR data}

Over three years of observation (2009-2011), 122 events of sea surface oil pollution as a result of ship discharges have been detected in the southeastern part of the Baltic Sea. Year-by-year numbers of oil spills are 37, 47, and 38, correspondingly. Total polluted areas are 150, 160, and $74 \mathrm{~km}^{2}$. Individual oil spill areas varied from 0.1 to $105 \mathrm{~km}^{2}$. Some statistics on oil spills in the southeastern part of the Baltic Sea revealed from satellite SAR data is shown below in Figs. 9-14. These are year-to year and average monthly numbers of spills detected in the southeastern Baltic Sea, numbers of spill revealed in different regions of the southeastern Baltic Sea over the three years of observations, annual size distribution of total area of the oil pollution, and total polluted areas for various regions of most intense pollution, described in this paper. Almost 75\% of oil spills had a size less than $2 \mathrm{~km}^{2}$ (Fig.14). Oil spills larger than $6 \mathrm{~km}^{2}$ are quite rare.

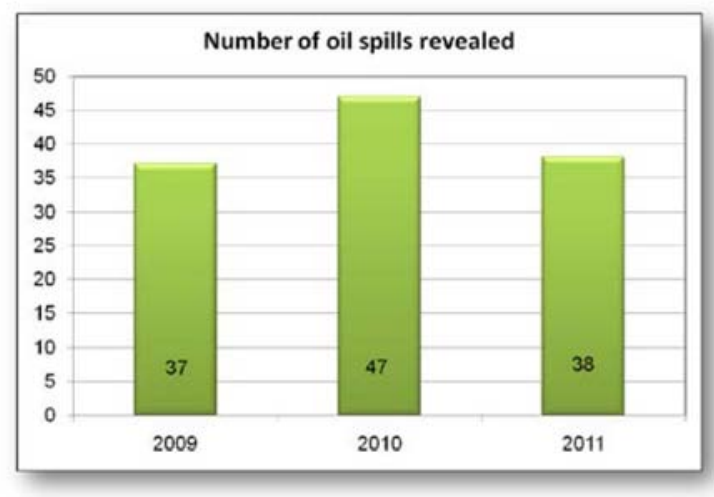

Figure 9. Year-to year distribution of a number of oil spills detected in the southeastern Baltic Sea

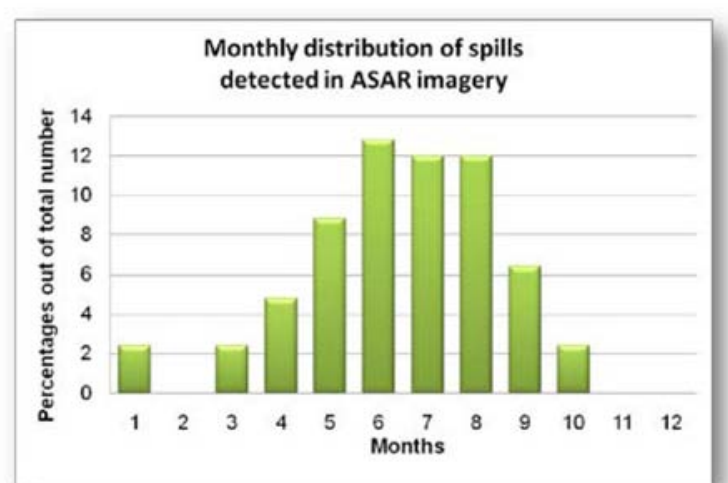

Figure 11. Seasonal distribution of oil spills detected in the southeastern Baltic Sea

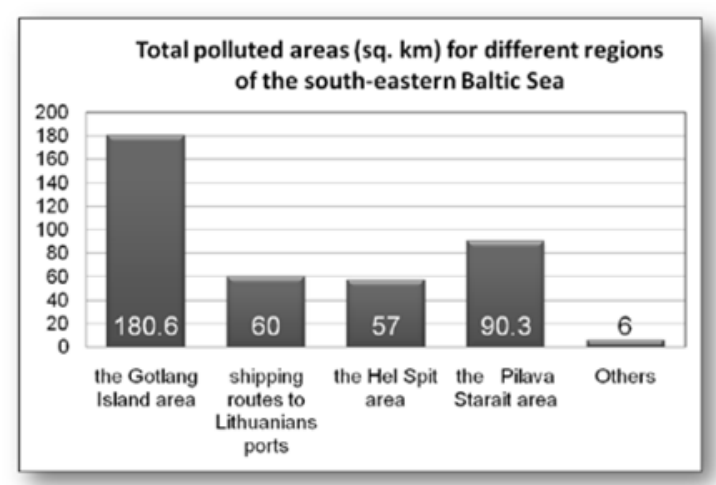

Figure 13. Total polluted areas $\left(\mathrm{km}^{2}\right)$ for different regions of the southeastern Baltic Sea

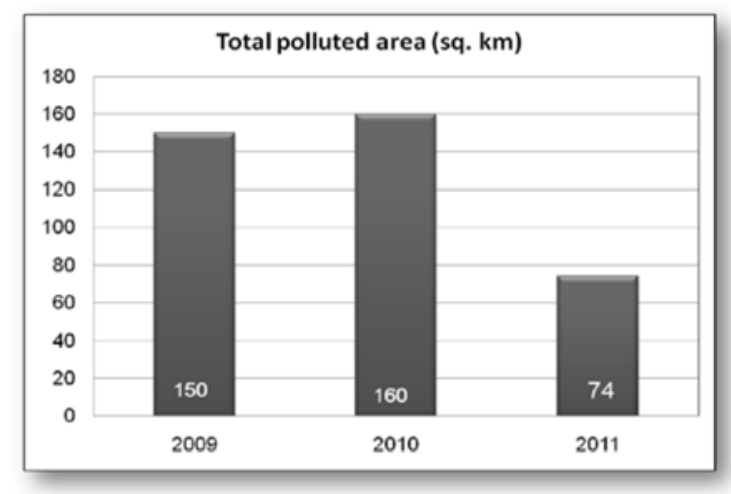

Figure 10. Year-to year total polluted area in the southeastern Baltic Sea

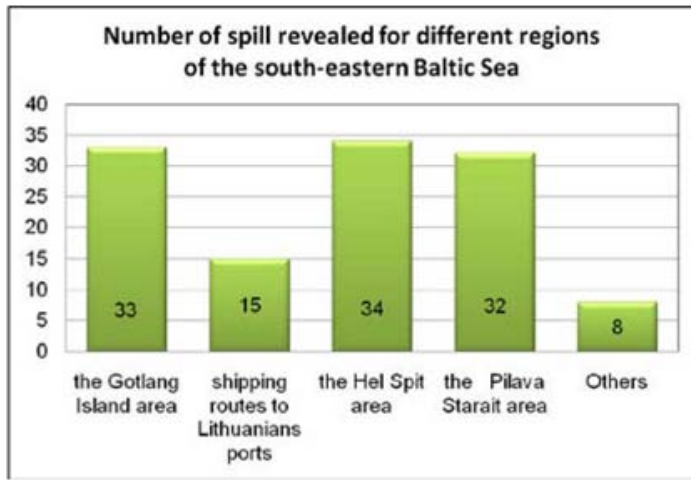

Figure 12. Total number of oil spills detected in different regions of the southeastern Baltic Sea

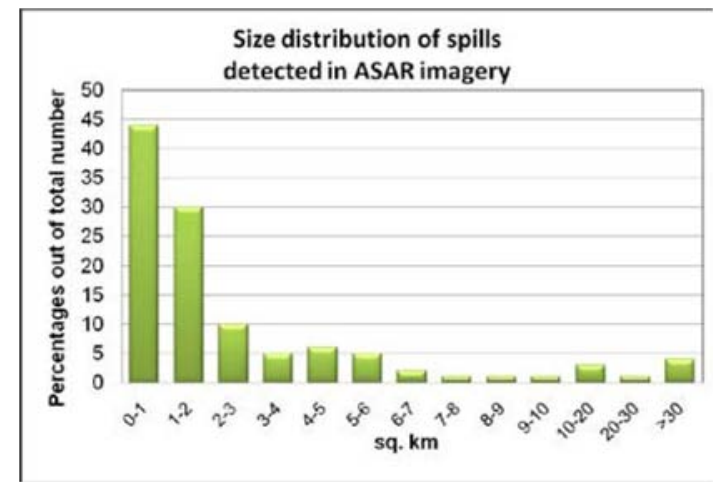

Figure 14. Size distribution of oil spills detected in the southeastern Baltic Sea 


\section{Conclusions}

The results of the operational monitoring performed in June 2004 - November 2005 (see a map in Fig. 15) were compared with the up-to-date situation (2009-2011). It can be concluded that the situation with the anthropogenic oil pollution in Baltic Sea have much improved last years. This fact is supported by other sources and data on oil pollution in the Baltic Sea (Kostianoy and Lavrova, 2014a,c).

It could be a result of increased control of various national and international organizations in the Baltic Sea countries on the sea pollution. The illegal ship discharges as well as outflows of local rivers and Pilava Strait continue to be the main sources of the oil pollution. The ship discharges traditionally take place at an anchorage site near the entrance to the Pilava Strait (Kaliningrad Canal), along the main navigation route eastward of the Gotland Island, along the shipping routes to the Klaipeda and Liepaja ports, and in the Hel Spit area.

Satellite radar imagery provides effective capabilities to monitor oil spills, in particular, in the Baltic Sea. Combined with satellite remote sensing of SST, sea level, chlorophyll concentration, mesoscale dynamics, wind and waves this observational system represents a powerful method for a longterm operational monitoring of ecological state of semi-enclosed seas especially vulnerable to oil pollution.

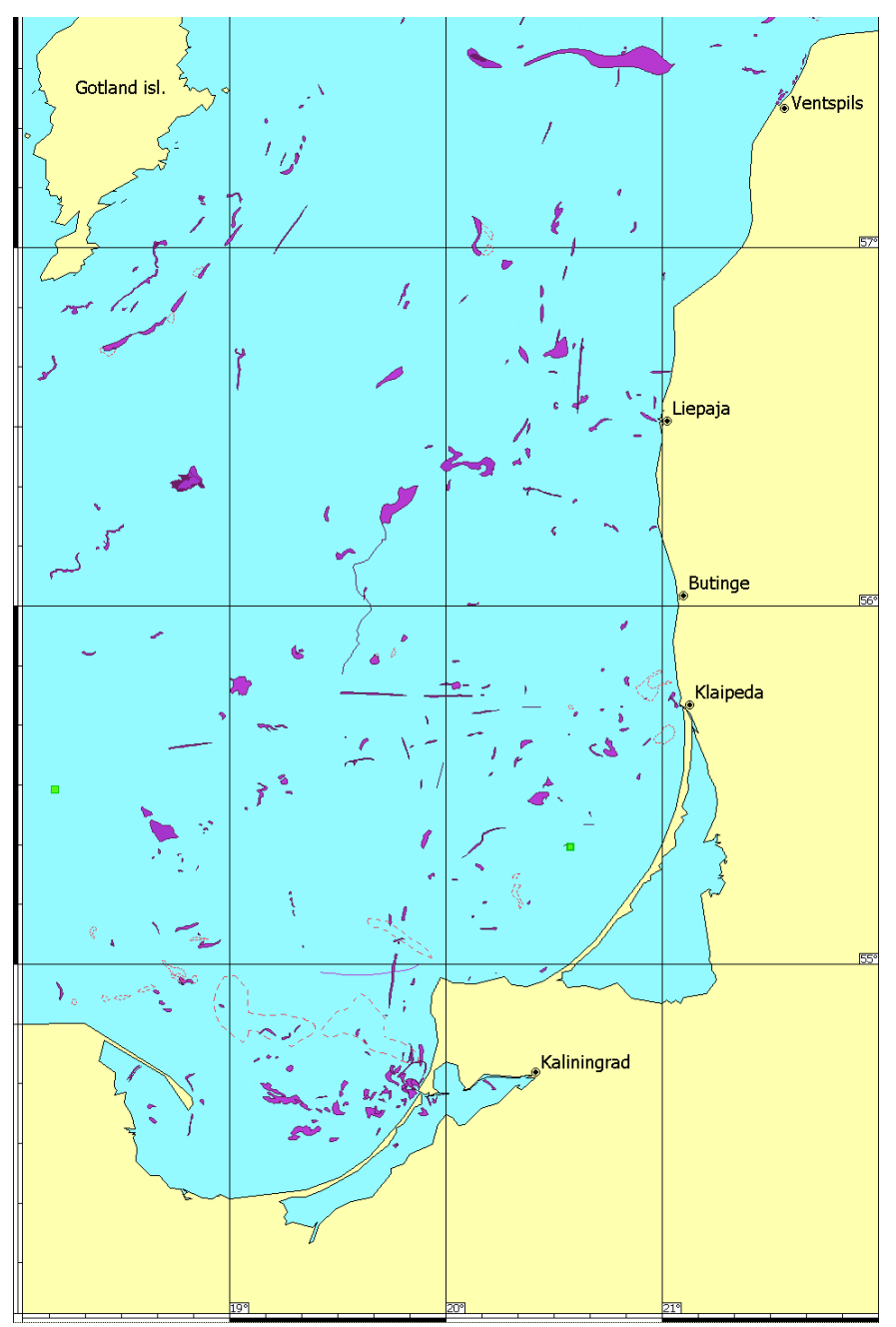

Figure 15. Map of all oil spills detected by the analysis of the ASAR ENVISAT and SAR RADARSAT imagery in June 2004 - November 2005(after Kostianoy et al., 2006)

\section{Acknowledgements}

The research was supported by the Russian Science Foundation under the project N 14-17-00555. Satellite radar data were provided by the European Space Agency in the framework of the C1P.6342, Bear 2775 and C1P.1027 projects. 


\section{References}

1. Alpers, W. and Huhnerfuss H. (1989). The damping of ocean waves by surface films: A new look at an old problem, Journal of Geophysical Research, 94, 6251-6265.

2. Brekke C., A. Solberg (2005) Oil spill detection by satellite remote sensing, Remote Sensing of Environment. 95, 1-13.

3. Espedal, H.A., Johannessen, O.M. (2000). Detection of oil spills near offshore installations using synthetic aperture radar (SAR), International Journal of Remote Sensing. 21(11), 2141-2144.

4. Espedal H, Wahl T., (1999) Satellite SAR oil spill detection using wind history information. International Journal of Remote Sensing. 20(1), 49-65.

5. Gade M. (2006). On the imaging of biogenic and anthropogenic surface films on the sea by radar sensors. In Marine Surface Films: Chemical Characteristics, Influence on Air-Sea Interactions, and Remote Sensing (Ed. Gade M., Huhnerfuss H. and Korenowski G.H.), Springer Heidelberg, pp. 189204.

6. Global Marine Oil Pollution Information Gateway (2012). Online at http://www.oils.gpa.unep.org/ (as of 10 June 2012).

7. Grishin N., Kostianoy A. (2012a) Satellite monitoring of suspended matter pollution resulted from the Nord Stream gas pipeline construction in Russian waters of the Baltic Sea in 2010-2011. International Water Technology Journal, V.2, N1, P.80-89.

8. Grishin N.N., Kostianoy A.G. (2012b) On satellite monitoring of suspended matter transport during the construction of an offshore gas pipeline Nord Stream in Russian waters of the Baltic Sea in 2010. Modern problems of remote sensing of the Earth from space, V.9, N 1, P. 167-175 (in Russian).

9. Grishin N.N., Kostianoy A.G. (2013) The use of satellite monitoring of suspended matter transport for the assessment of transboundary environmental impact of construction the Russian section of the offshore gas pipeline Nord Stream. Modern problems of remote sensing of the Earth from space, V.10, N 1, P. 303-319 (in Russian).

10. Jenkins, A.D. and Jacobs, S.J. (1997). Wave damping by a thin layer of viscous fluid, Phys. Fluids. 9(5), 1256-1264.

11. Kostianoy, A.G. and Lavrova, O.Yu. (Eds.) (2014a) Oil pollution in the Baltic Sea. Springer-Verlag, Berlin, Heidelberg, New York. V27. 268 pp.

12. Kostianoy, A.G. and Lavrova, O.Yu. (2014b) Introduction. In: Oil pollution in the Baltic Sea. (Eds.) A.G. Kostianoy and O.Yu. Lavrova, Springer-Verlag, Berlin, Heidelberg, New York, V27, 1-13.

13. Kostianoy, A.G. and Lavrova, O.Yu. (2014c) Conclusions. In: Oil pollution in the Baltic Sea. (Eds.) A.G. Kostianoy and O.Yu. Lavrova, Springer-Verlag, Berlin, Heidelberg, New York, V27, 249-263.

14. Kostianoy A., Lavrova O, Mityagina, M., Bocharova, T., Litovchenko K., Lebedev S., Stanichny S., Soloviev D., Sirota A. (2007) Complex Monitoring of Oil Pollution in the Baltic, Black and Caspian Seas. In Proc. 'Envisat Symposium 2007'. ESA-SP-636. (CD-ROM), European Space Agency, Noordwijk, The Netherlands. 2007.

15. Kostianoy, A.G., Lavrova, O.Yu., Mityagina, M.I., Solovyov, D.M. and Lebedev, S.A. (2014a). Satellite monitoring of oil pollution in the Southeastern Baltic Sea. In: Oil Pollution in the Baltic Sea, Springer-Verlag, Heidelberg, V27, pp.125-154.

16. Kostianoy A.G., Lavrova O.Yu., Mityagina M.I., Solovyov D.M. (2014b) Satellite monitoring of the Nord Stream gas pipeline construction in the Gulf of Finland. In: Oil Pollution in the Baltic Sea, (Eds.) A.G. Kostianoy and O.Yu. Lavrova, Springer-Verlag, Berlin, Heidelberg, New York, V27, P. 221-248.

17. Kostianoy A.G., Lebedev S.A., Litovchenko K.Ts., Stanichny S.V., Pichuzhkina O.E. (2005). Oil spill monitoring in the Southeastern Baltic Sea. Environmental Research, Engineering and Management. 3(33), 73-79.

18. Kostianoy A.G., Litovchenko K.Ts., Lavrova O.Yu., Mityagina M.I., Bocharova T.Yu., Lebedev S.A., Stanichny S.V., Soloviev D.M., Sirota A.M Pichuzhkina O.E. (2006). Operational satellite monitoring of oil spill pollution inthe southeastern Baltic Sea: 18 months experience. Environmental Research, Engineering and Management. 4(38), 70-77.

19. Lavrova O.Yu, Kostianoy A.G., Lebedev S.A., Mityagina M.I., Ginzburg A.I., Sheremet N.A. (2011) Complex satellite monitoring of the Russian seas. Moscow: IKI RAN, 470 pp. (in Russian).

20. Lavrova O., Mityagina M., Bocharova T., Kostianoy A., Krovotyntsev V. (2009) Multisensor approach to operational oil pollution monitoring in coastal zones, In Proc. IEEE Int. Geoscience and Remote Sensing Symposium (IGARSS’09), 3, III-1386-III-1389. 
21. Mityagina M. and Churumov A. (2006). Radar backscattering at sea surface covered with oil films. In: Global Developments in Environmental Earth Observation from Space (Ed. A. Marcal). Millpress. Rotterdam. Netherlands, pp.783-790.

22. Mityagina MI, Lavrova OYu, Kostianoy AG (2012) Long term satellite monitoring of the oil spillage pollution in the south-eastern Baltic Sea. (2012). ESA-SP-709 (CD-ROM), ESA Publications Division, European Space Agency, Noordwijk, The Netherlands.

23. Shcherbak, S.S., Lavrova, O.Y., Mityagina, M.I., Bocharova, T.Y., Krovotyntsev, V.A. and Ostrovskii, A.G. (2008). Multisensor satellite monitoring of seawater state and oil pollution in the northeastern coastal zone of the Black Sea, International Journal of Remote Sensing. 29(21), 6331 6345. 